\title{
An Extended Quality Function Deployment Incorporating Fuzzy Logic and GDM Under Different Preference Structures
}

\author{
Gülçin Büyüközkan ${ }^{*}$, Gizem Çifçi \\ Industrial Engineering Department, Faculty of Engineering and Technology, Galatasaray University, \\ Ortaköy, Istanbul, Turkey \\ E-mail: gulcin.buyukozkan@gmail.com
}

Received 2 January 2014

Accepted 8 January 2015

\begin{abstract}
The paper proposes a fuzzy logic-based group decision making (GDM) approach, which can be used for quality function deployment (QFD) in the development of product improvement strategies. Decision makers can state their preferences in various ways, including incomplete preferences which are difficult to evaluate in a coherent way. We extend the QFD methodology by using a GDM approach which considers multiple preference formats and incomplete information. Finally, a numerical analysis for "Portable Entertainment and Game Systems" design is given to verify the feasibility of the model.
\end{abstract}

Keywords: Incomplete preference relations, multiple preference formats, fuzzy sets, group decision making, house of quality, quality function deployment.

\section{Introduction}

A good product design requires designers to know what is being designed, and what end-users expect from the product. As a systematic approach for design, Quality Function Deployment (QFD) is based on awareness of customer requirements, and is integrated with functional groups of a business. The ultimate goal of QFD is to use objective procedures with increasing detail during the development stages of a product ${ }^{1}$. It aims to translate quality criteria, which can be subjective, into more quantifiable, objective and measureable ones so that the criteria can be made use of for designing and manufacturing the product accordingly. QFD makes use of the "House of Quality" (HOQ) ${ }^{2,3}$ matrix, which is basically a conceptual construct for identifying customer needs (CNs) for the design process and setting priorities of design requirements (DRs) to satisfy them. QFD has proved its usefulness in product development since many years. ${ }^{4-10}$

QFD is used for defining how and where product development priorities should be assigned. It involves inherently vague inputs from individuals as a result of human perception, judgment and evaluation. Therefore, data collected from decision makers on the importance of requirements are usually subjective and uncertain. To reduce the bias and partiality that can faced during the decision process, QFD widely utilizes group decision making $(\mathrm{GDM})^{11-14}$ and fuzzy set theory ${ }^{15-19}$. In a GDM process, different alternatives are assessed by a predefined group of decision makers (DMs) who without doubt differ in their education, background, competence, experience, and character. DMs from different environments and qualifications may provide

* Corresponding Author. Phone: +90 212227 4480; Fax: +90 2122595557. 


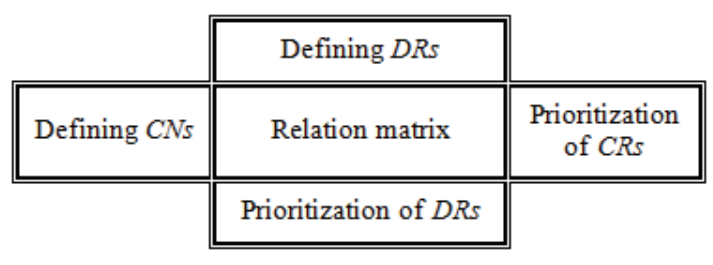

Fig. 1. Proposed HOQ Matrix

their judgments on alternatives in different formats (e.g. numeric or linguistic), making it more difficult to obtain an accurate quantitative evaluation.

It must be pointed out that DMs may not always have exact information about the problem. They also may not always be in a position to clearly compare exiting alternatives due to factors such as time constrict, insufficient knowledge, - motivation deficiency, etc. Statement of preferences - in different formats has -took attention in literature $\mathrm{e}^{20-26}$. Although such constraints in the evaluation process cannot be handled effectively without incomplete preference relations, Büyüközkan and Çifçi ${ }^{27}$ uniquely addressed multiple formatted preferences that handle incomplete information.

The goal of the study is to adopt an integrated QFD methodology with GDM approach. The approach incorporates incomplete information and multiple preference formats, and combines various expressions into a single final group decision by utilizing the fuzzy set theory. ${ }^{28}$ As the validation of the approach, a HOQ application is presented for "Portable Entertainment and Game Systems". Considering that the incomplete and multiple preferences techniques are not prevalent in literature, the main contribution of this study is that it effectively combines both techniques with QFD for product development.

Section 2 of the paper will provide a literature survey for HOQ, GDM, multiple preference formats and incomplete preference relations. In Section 3, the proposed approach for QFD is introduced. An application of the fuzzy logic based GDM approach is given in the Section 4 and the Section 5 closes the discussion with concluding remarks.

\section{Literature Survey}

\subsection{House of Quality}

QFD basically has three goals; to prioritize spoken and unspoken $\mathrm{CNs}$; translate these $\mathrm{CNs}$ into technical specifications (i.e. DRs); and to establish and bring a quality product or service to the market by targeting efforts on customer expectations and needs. QFD can be seen as a tool that helps businesses to focus on what customers believe to be substantial and to ensure that these specifications are met in the last product/service. To accomplish this objective, a series of matrices are used. The basic benefits of QFD are decreased design costs and development time ${ }^{30,31}$. It also improves communication and cohesion among the product development staff and helps consolidating design decisions in early stages of development efforts ${ }^{33}$.

HOQ is one of the products of QFD. With HOQ, "what customers want" versus "how these wants can be given to them" can be visually compared in a short time. When a product development team initiates a QFD process, the first matrix used is $\mathrm{HOQ}$, which is considerably strong because of the amount of information that can be documented and analyzed ${ }^{34}$. In constructing the HOQ matrix (see Figure 1), the first thing to do is to acquire the "voice of customers" as inputs of CNs. These CNs are then expressed quantitatively and comparisons are done for prioritization. As another key step, it is determined and analyzed which CNs depend on which DRs. Afterwards, a relation matrix is established between CNs and DRs. In the final stage of constructing HOQ, DRs' priorities are found and goals are determined. Despite its popularity, there have been no coherent or uniform QFD concepts - so far, which can be confusing for nonspecialists. ${ }^{35}$ The proposed HOQ procedure is explained in Section 4 step by step.

\subsection{Group Decision Making}

In traditional QFD, several people are involved who are required to express and prioritize their preferences $(\mathrm{CNs})^{36}$, which can be difficult for when specifying priorities to customer preferences. This process can lead to remarkably diverse and biased expressions based on the profile and prior experience of DMs. In this paper, the aim is to present an approach for an enhanced consensus reaching process by fusing GDM with a group-customer preference system.

When taking decisions with regards to expectations of customers, GDM processes can be subject to uncertainty inherent to customers' preferences. In literature, fuzzy GDM approaches have been studied to 
deal with such challenges ${ }^{37-40}$. The fuzzy set theory can be utilized in overcoming the decision making problems for treating uncertainty. Lingual expressions are considered as the natural statement of the preference or decision such as satisfied/dissatisfied. As the DM views are based on lingual parameters, the evaluation of their opinions must be handled with in a vague, fuzzy environment. For this reason, this paper includes the fuzzy GDM which provides the decision making process to be reasonable and comprehensive.

Several authors have previously studied fuzzy GDM approach in QFD. Bevilacqua, Ciarapica, and Giacchetta $^{41}$ studied a fuzzy QFD based on the GDM approach to select clutch plate suppliers. Chin, Wang, Yang, and Poon $^{42}$ introduced a QFD approach with group decision under uncertainty, based on evidential reasoning. Liu ${ }^{43}$ studied fuzzy GDM in QFD and focused on consumer perception of risk. Another fuzzy GDM study is put forward in QFD by $\mathrm{Kuo}, \mathrm{Wu}$, and Shieh $^{16}$ for the consideration of environmental aspects in the design of toner cartridges. Similarly, Zhang and $\mathrm{Chu}^{24}$ proposed a fuzzy GDM in QFD for complex product development. They applied their approach on a case of equipment selection for horizontal directional drilling . Kwong, Chen and $\mathrm{Choy}^{44}$ proposed a novel fuzzy GDM approach which integrates the fuzzy weighted average method with a consensus ordinal ranking method to prioritize engineering characteristics in QFD under uncertainty. Lin, Huang and $\mathrm{Yeh}^{45}$ used fuzzy GDM and a QFD method to analyze various service evaluation criteria in tourism service innovations. Recently, Chen, Ko and Tseng ${ }^{46}$ proposed an adapted fuzzy clustering methodology for reaching consensus in a QFD team. Zaim et al. ${ }^{47}$ also studied fuzzy decision making in QFD for product development.

It is of primary importance to achieve consensus in a group of different opinions, especially when uncertainty exists. Despite their value because of their use of GDM methods applied in fuzzy environments, literature has so far failed to sufficiently address the issue of handling different types of information. This paper suggests that currently used methods for GDM in QFD should also deal with DMs who have diversified preferences.

\subsection{Multiple Preference Formats}

In the traditional GDM process, DMs provide their preferences by using decision matrices, with which the
HOQ is constructed. Considering DMs' different background and evaluation methods, their preferences can be communicated in various ways. Under such complex circumstances, agreeing on a group decision consensus is a challenging task. Research on using different preference formats is reviewed below.

Chiclana, Herrera, and Herrera-Viedma ${ }^{48}$ integrated three representation models (preference ordering, utility function, fuzzy preference relation) in a fuzzy multipurpose decision making problem, where DMs provide varied information on alternatives. In another study, Herrera, Herrera-Viedma, and Chiclana $^{48}$ proposed a GDM approach established on multiplicative preference relations. Their model is based on relations as preference ordering, utility values, and multiplicative preference relation. Zhang, Chena and Chong ${ }^{22}$ determined criteria weights for consolidating decisions using multiple preference formats, where they studied a uniformity and aggregating method with the aim to conveniently and accurately generate the final decision with higher DM satisfaction. Herrera, Martinez, and Sanchez $^{50}$ also investigated a GDM problem, where DMs expressed individual preferences by using various scales. They proposed a method for aggregation in order to better manage heterogeneous preference relations, including numerical-valued, interval-valued and linguistic-valued information.

Kwok, Zhou, Zhang and $\mathrm{Ma}^{51}$ came up with a fuzzy multi-attribute decision making model that makes use of different preference formats; namely preference ordering, utility vector, linguistic term vector, selected subset, fuzzy selected subset, fuzzy preference relation, and normal preference relation. $\mathrm{Xu}^{52}$ introduced a multiple-attribute GDM approach in which DMs express their opinions by different uncertain-preference formats such as interval utility values, interval fuzzyand interval multiplicative preference relations. In another study, $\mathrm{Xu}^{53}$ presented a GDM method which is based on different preference relations types. $\mathrm{Xu}$ and Chen ${ }^{54}$ investigated multiple-attribute GDM problems with specific uncertain preference structures. They used utility vector, multiplicative preference relation, and fuzzy preference relation as preference structures.

Abedin, Chao, Godwin and Arochena ${ }^{55}$ proposed a multi-issue negotiation approach for service level agreement using preference ordering. Similarly seven preference formats which $\mathrm{Xu}^{52}$ studied are provided to consumers.. Dong, Xua and $\mathrm{Yu}^{56}$ proposed a GDM that 
is based on linguistic, multiplicative and fuzzy preference relations.

To further reduce the bias in the GDM process, $\operatorname{Lin}^{57}$ provided an integrated 2-stage model using fuzzy multiple preferences. Initially, based on the respective linguistic preferences, information is united on the alternatives. Afterwards by computing collective performance values, problems of integrating individual fuzzy choices are solved. In the second stage, the alternatives - are selected based on the collective performance values that were found in the first stage. The aim of their decision procedure was to obtain subjective fuzzy cognitions as preference values of all DMs.

Although these studies using multiple preferences are highly capable of gathering different decision formats from DMs, they can be inadequate in handling the lack of information. In the next section (2.4), it can be seen that DMs and interviewers can face such situations. To eliminate such hurdles, this study suggests that the studied methods should also deal with DMs who express incomplete preferences.

\subsection{Incomplete Preference Relations}

In decision making processes, DMs are required to evaluate criteria and alternatives with complete linguistic preference relations. Sometimes, however, it might be hard to collect all such preference relations. Considering that every one of the selected experts have his/her own experience and views, it is possible that an expert does not have complete information about the question. There can be situations where DMs are not able to effectively state any preference among the available options. This might happen when the DM does not have complete or adequate data or when he/she is not able to decide which options are superior to others ${ }^{58}$. Considering that QFD involves GDM, such issues are possible during the evaluation process of CNs.

Incomplete judgments are another perspective for linguistic preference relations considering DMs in an evaluation group may -have inadequate information. Therefore, incomplete preferences should be considered in an evaluation process. By using incomplete preference relations, evaluation limitations can effectively be managed, improving the quality and strength of the evaluation.

Scientific papers studying incomplete information are in progress. To deal with the problem of incomplete or inconsistent information, Alonso et al. ${ }^{59}$ came up with a decision support approach to obtain consistent linguistic preference relations. $\mathrm{Xu}^{, 60,61,62}$ studied the incomplete linguistic preference relations and different types of integrated incomplete linguistic preference relations in GDM. They proposed a GDM model which uses intuitionistic and incomplete preference relations. Herrera-Viedma et al. ${ }^{58,63}$ introduced a GDM model for reaching consensus using incomplete fuzzy preference relations, while Fedrizzi and Giove ${ }^{64}$ studied the techniques of incomplete pair-wise comparison and optimization of consistency. Chiclana, Herrera-Viedma, and Alonso ${ }^{65}$ compared different methodologies used for calculating missing pair-wise preference values based on additive consistency. In another paper, Wang, Peng, Hsu and Chang ${ }^{66}$ examined the use of incomplete linguistic preference relations in a case of internet shops performance. Wang and Chen ${ }^{67}$ discussed incomplete fuzzy linguistic preference relations under uncertainty for the selection of a global supplier. Porcel and Herrera-Viedma $^{68}$ proposed a method to deal with incomplete information in a fuzzy linguistic recommender system for digitalized university libraries. Cabrerizo et al. ${ }^{69}$ introduced a novel iterative selection approach to estimate missing information to handle incomplete fuzzy linguistic information. In another study by Cabrerizo, Pérez, and Herrera-Viedma ${ }^{70}$, a consensus model is formulated that focuses on incomplete unbalanced fuzzy linguistic information, which again utilized an iterative procedure to measure consistency based on additive transitivity. Recently, $\mathrm{Xu}^{71}$ proposed a novel method to work out GDM problems in the following four formats of incomplete preference relations: multiplicative, fuzzy, additive linguistic, and multiplicative linguistic preference relations. His study aimed to find the closest collective opinion using an optimization model that calculates the collective ranking values of the available alternatives. Chen, Lin and Lee ${ }^{72}$ introduced a GDM approach using incomplete fuzzy preference relations in which the consistency calculation is based on the additive and order property. Liu and $\mathrm{Wang}^{73}$ also studied a consensus model for GDM with incomplete interval fuzzy preference relations. 


\section{An Integrated Different Fuzzy Preference} Structures in GDM Approach for QFD

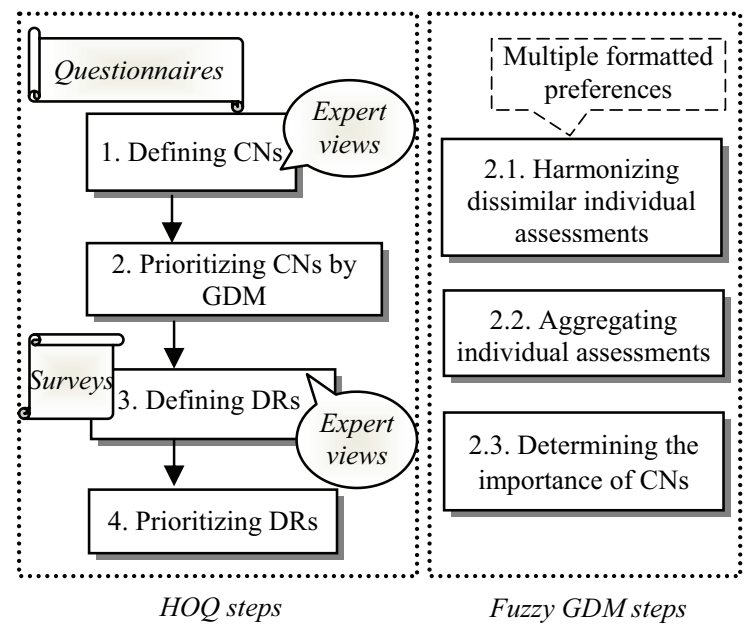

Fig. 2. Proposed Approach for QFD

Although the proposed framework in this study is novel, QFD literature employs multiple preference formats. As a first, Büyüközkan and Feyzioglu ${ }^{11}$ extended the QFD methodology by combining different approaches such as preference ordering, fuzzy pair-wise comparison, optimal subset method, utility analysis and linguistic preference relations. Following their introduction of GDM with multiple preference formats, Büyüközkan, Feyzioğlu and Ruan ${ }^{23}$ presented a fuzzy GDM model that fused multiple preference styles to respond to CRs in QFD. Similarly, Feyzioglu and Büyüközkan ${ }^{4}$ introduced an integrated GDM approach for new product development based on multiple preference formats and the Choquet integral techniques. Distinctly from authors' other studies, they additionally proposed the Choquet integral technique as a benchmarking procedure to rate alternative systems and find out which criteria should be improved. Zhang and $\mathrm{Chu}^{13}$ focused on the fuzzy GDM for multi-format and multigranularity linguistic assessments in QFD. In their paper, DMs provide opinions in terms of fuzzy pairwise comparisons and linguistic preference relations formats. To aggregate those judgments, a GDM approach is presented which incorporated the optimization models of logarithmic least squares and weighted least squares. Wang and Xiong ${ }^{74}$ came up with a linguistic-based, integrated GDM approach that directly calculated using words. Their approach aimed to reduce the risk of information loss and to handle a number of types and multi-granularity linguistic judgments provided by DMs in QFD. Recently, $\mathrm{Li}$ et al. ${ }^{26}$ introduced an integrated approach consisting of GDM, multi-format preferences, and 3 types of least square models to obtain the sale points of $\mathrm{CNs}$ for the purpose of dealing with the relative satisfaction levels and multiple preference information. Wang ${ }^{75}$ also studied relative preferences in fuzzy QFD by a criteria weighting approach.

However, researches seldomly focused on incomplete preferences. There is even more limited number of researches in the literature that utilize incomplete preferences in the field of QFD. Lately, Urena et al. ${ }^{76}$ studied incomplete fuzzy and multiplicative preference relations in multi-person decision making to deal with the missing preferences.

Firstly, Han, Kim and $\mathrm{Choi}^{77}$ examined incomplete preference relations with linear partial ordering method for evaluating information in QFD. A key factor of the methodology is to find weights of missing $\mathrm{CNs}$ and to evaluate relationship values of $\mathrm{CNs}$ between weights of DRs and then to prioritize engineering characteristics. Their view is revised and enhanced in Büyüközkan and Çifçi's ${ }^{25}$ study and a new GDM approach is introduced that included DMs' incomplete information by using the fuzzy set theory. Büyüközkan and Çifçi applied their proposed approach to a real case of collaborative software development.

Figure 2 depicts the proposed approach and the calculation procedure is provided below.

Step 1 - "Whats - Specifying the CNs": This step is about identifying what customers want and need, which can also be named as the voice of customers. In this step, CRs are defined and placed on the left side of the HOQ. Information for identifying these CRs can be collected via questionnaires, literature surveys, or expert views.

Step 2 - "Prioritizing CNs": In this step, CNs are compared and prioritized based on their individual importance degrees. These $\mathrm{CN}$ importance degrees will assist the design analysis step. Considering that the info acquired from DMs may not be accurate enough to effectively determine the importance degrees, this paper employs a fuzzy GDM approach.

Step 2.1 - "Harmonizing Different Relative Evaluations": DMs are supposed to provide their importance rankings based on the formats below:

1. DMs can provide a pair-wise comparison matrix, where each term is characterized as the relative 
importance of one $\mathrm{CN}$ against others. This can be obtained with the help of a ratio scale which is proposed by Saaty $^{73}$ originally. When $\mathrm{CN} \mathrm{i}$ and $\mathrm{j}$ are equally important, $x_{i j}=1$. When $\mathrm{i}$ is definitely much more important than $\mathrm{j}$, then $x_{i j}=9$. Intermediate importance values are ordered from 2 to 8 . The matrix is multiplicatively reciprocal: $x_{i j}=\mathrm{a}$ and $x_{j i}=1 / \mathrm{a}$ for all a $\in$ $\{1, \ldots, 9\}$.

2. DMs can provide an ordered vector $(\mathrm{o}(1), \ldots$, $o(N)$ ), where o(i) is the importance ranking ( 1 is the most and $\mathrm{N}$ is the least important) of $\mathrm{CN}$ i. This ordering can be converted into a relative importance relation as the following;

$$
x_{i j}=9^{u_{i}-u_{j}} \text { for all } 1 \leq \mathrm{i} \neq \mathrm{j} \leq \mathrm{N}
$$

where $u_{i}=(\mathrm{N}-\mathrm{o}(\mathrm{i})) /(\mathrm{N}-1)$. According to Herrera et $\mathrm{al}^{48}$, this type of function can be acquired by giving an importance/utility value to each alternative. If the position of alternative goes lower, than the utility value $\mathrm{u}_{\mathrm{i}}$ will be higher. It can be assumed that the preference of the best alternative over the worst is the highest allowed, which is 9 . So for instance, if $\mathrm{o}(\mathrm{i})=1$ and $\mathrm{o}(\mathrm{j})=\mathrm{N}$ then it is presumed that $x_{i j}=9$. For detailed computations of formula, Herrera et al. ${ }^{48}$ can be studied.

3. DMs can provide an importance degree vector $\left(\mathrm{u}_{1}\right.$, $\left.\ldots, u_{N}\right)$ where $u_{i} \in[0,1] i=1, \ldots, N$.The closer $u_{i}$ is to 1 , the more signicifant it will be. . This vector can be converted into relative importance relation as;

$$
x_{i j}=u_{i} / u_{j} \text { for all } 1 \leq \mathrm{i} \neq \mathrm{j} \leq \mathrm{N} .
$$

Commentating $\mathrm{u}_{\mathrm{i}} / \mathrm{u}_{\mathrm{j}}$ as a ratio of the preference intensity for $x_{i}$ to that of $x_{j}$, it can be assumed that $\mathrm{x}_{\mathrm{i}}$ is $\mathrm{u}_{\mathrm{i}} / \mathrm{u}_{\mathrm{j}}$ times good as $x_{j}$. This is one of the basic functions to acquire the intensity of preference which is proposed by Saaty ${ }^{78,79}$.

4. DMs can provide a linguistic importance vector $\left(\mathrm{s}_{1}\right.$, $\ldots, \mathrm{s}_{\mathrm{N}}$ ) where $\mathrm{s}_{\mathrm{i}}$ with $\mathrm{i}=1, \ldots, \mathrm{N}$ can be one of the following: "Not Important (NI), Some Important (SI), Moderately Important (MI), Important (I) and Very Important (VI)." Considering a fuzzy triangular number can be stated as $\left(a_{i}, b_{i}, c_{i}\right)$ where $b_{i}$ is the most encountered value, fuzzy membership functions for $\mathrm{s}_{\mathrm{i}}$ can be $\mathrm{NI}=(0.00,0.00,0.25), \mathrm{SI}=(0.00,0.25,0.50)$, $\mathrm{MI}=(0.25,0.50,0.75), \mathrm{I}=(0.50,0.75,1.00)$ and $\mathrm{VI}=$
$(0.75,1.00,1.00)$. The linguistic term vector can be converted into a relative importance relation as;

$$
x_{i j}=9^{b_{i}-b_{j}} \text { for all } 1 \leq \mathrm{i} \neq \mathrm{j} \leq \mathrm{N}
$$

5. DMs can state the importance of $\mathrm{CNs}$ without identifying the degree explicitly. In this situation,

$$
x_{i j}=9 \text { and } x_{j i}=1 / 9 \text {, if } \mathrm{i} \text { is more important than } \mathrm{j}
$$

and $x_{i j}=1$ if nothing mentioned.

6. DMs can prefer to choose only a subset of CNs (R') that is important for them. For this case, the CNs in the set $\mathrm{R}^{\prime}$ have equal importance and they are dominant to remaining $\mathrm{CNs}$ in $\mathrm{R} / \mathrm{R}$ '. The $\mathrm{CNs}$ in $\mathrm{R} / \mathrm{R}^{\prime}$ also have equal importance to each other. The preference relation can be described as;

$$
x_{i j}=\left\{\begin{array}{c}
9, i \in R^{\prime}, j \in R / R^{\prime} \\
1 / 9, i \in R / R^{\prime}, j \in R^{\prime} \\
1, \quad \text { otherwise }
\end{array}\right.
$$

for all $1 \leq \mathrm{i} \neq \mathrm{j} \leq \mathrm{N}$.

7. DMs can prefer to choose only a subset of $\mathrm{CNs}$ ( $\bar{R}$ ) and provide the importance of the requirements linguistically. Identically, with the notation in Eq. (3), the relative importance relation can be stated as

$$
x_{i j}=\left\{\begin{array}{c}
9^{b_{i}-b_{j}}, \quad i, j \in R \\
9^{b_{i}-0.5}, i \in \bar{R}, j \in R / \overline{R^{\prime}} \\
1, \quad i, j \in R / \bar{R}
\end{array}\right.
$$

for all $1 \leq \mathrm{i} \neq \mathrm{j} \leq \mathrm{N}$.

8. DMs can provide an incomplete pair-wise comparison matrix, where some terms can be missing. First of all, a comparison scale is required to measure the importance degrees of the CNs.For this reason, fuzzy linguistic variables $\widetilde{p}_{i j}=\left(p_{i j}^{l}, p_{i j}^{m}, p_{i j}^{u}\right)$ (See Table 1) are used. Here $\widetilde{p}_{i j}$ indicates the importance between the compared criteria (importance of $\mathrm{i}$ over $\mathrm{j}$ ) where $p_{i j}^{l}$ and $p_{i j}^{u}$ are the lower and upper bounds of $\widetilde{p}_{i j}$, respectively, and $p_{i j}^{m}$ is median value where $i=j=1,2, \ldots, n$. 
Table 1. Linguistic terms for evaluation.

\begin{tabular}{ccc}
\hline Linguistic term & Abbreviation & $\begin{array}{c}\text { Fuzzy Membership } \\
\text { Function }\end{array}$ \\
\hline None & N & $(0,0,1)$ \\
Very Low & VL & $(0,0.1,0.2)$ \\
Low & L & $(0.1,0.2,0.3)$ \\
Fairly Low & FL & $(0.2,0.3,0.4)$ \\
More or less Low & ML & $(0.3,0.4,0.5)$ \\
Medium & M & $(0.4,0.5,0.6)$ \\
More or less Good & MG & $(0.5,0.6,0.7)$ \\
Fairly Good & FG & $(0.6,0.7,0.8)$ \\
Good & G & $(0.7,0.8,0.9)$ \\
Very Good & VG & $(0.8,0.9,1)$ \\
Excellent & E & $(0.9,1,1)$ \\
\hline
\end{tabular}

As soon as the DMs establish and assess the incomplete pair-wise comparison matrices of interdependent elements, evaluated preferences are defuzzified using Eq. (7);

$$
F\left(\widetilde{p}_{i j}\right)=1 / 2 \int_{0}^{1}\left(\inf _{x \in \Re} \widetilde{p}_{i j}+\sup _{x \in \Re} \widetilde{p}_{i j}\right) d \alpha
$$

Consequently, missing elements can be calculated in a DM's incomplete preference . Considering a reciprocal preference relation, Eqs. (8) to (10) can be used to compute an estimated preference value $p_{i j}(i \neq$ j) using other preference degrees ${ }^{63}$

From $p_{i j}=p_{i y}+p_{y j}-0.5$, we achieve the estimate

$$
c p_{i j}^{y 1}=p_{i y}+p_{y j}-0.5
$$

From $p_{y j}=p_{y i}+p_{i j}-0.5$, we achieve the estimate

$$
c p_{i j}^{y 2}=p_{y j}-p_{y j}+0.5
$$

From $p_{i y}=p_{i j}+p_{j y}-0.5$, we achieve the estimate

$$
c p_{i j}^{y 3}=p_{i y}-p_{j y}+0.5
$$

The preference value of one element over itself is supposed to be equal to 0.5 .

For incomplete preference relation, the sets below can be used to estimate its consistency level:

$$
\begin{aligned}
& H_{i j}^{1}=\{\mathrm{y} \neq \mathrm{i}, \mathrm{j} \mid(\mathrm{i}, \mathrm{y}),(\mathrm{y}, \mathrm{j}) \in \mathrm{EV}\} \\
& H_{i j}^{2}=\{\mathrm{y} \neq \mathrm{i}, \mathrm{j} \mid(\mathrm{y}, \mathrm{i}),(\mathrm{y}, \mathrm{j}) \in \mathrm{EV}\} \\
& H_{i j}^{3}=\{\mathrm{y} \neq \mathrm{i}, \mathrm{j} \mid(\mathrm{i}, \mathrm{y}),(\mathrm{j}, \mathrm{y}) \in \mathrm{EV}\}
\end{aligned}
$$

where $\mathrm{EV}$ is the set of evaluated alternatives by the expert, and $H_{i j}^{1}, H_{i j}^{2}, H_{i j}^{3}$ are the sets of intermediate alternative $a_{y}(y \neq i, j)$ that can be used to estimate the preference value $p_{i j}(\mathrm{i} \neq \mathrm{j})$ using Eq. (11) to (13), respectively. The consistency level $C L_{i j}$, related with a preference value $p_{i j}(\mathrm{i} \neq \mathrm{j}) \in \mathrm{EV}$,

$$
C L_{i j}=\left(1-\alpha_{i j}\right) \cdot\left(1-\varepsilon p_{i j}\right)+\alpha_{i j} \cdot \frac{C P_{i}+C P_{j}}{2}, \alpha_{i j} \in[0,1](14)
$$

is described as a linear combination of the average of the entirety values interrelated with the two alternatives involved in that preference degree $\mathrm{CP}_{\mathrm{i}}$ and $\mathrm{CP}_{\mathrm{j}}$,

$$
C P_{i}=\frac{\# E V}{2(n-1)}
$$

where $\# E V$ is the number of known preference values. Its related error $\varepsilon p_{i j}$ can be computed as in Eq. (16)

$$
\varepsilon p_{i j}=\frac{2}{3} \cdot \frac{\varepsilon p_{i j}^{1}+\varepsilon p_{i j}^{2}+\varepsilon p_{i j}^{3}}{K}
$$

where

$$
\varepsilon p_{i j}=\begin{gathered}
\frac{\sum_{y \in H_{i j}^{h}}\left|c p_{i j}^{y h}-p_{i j}\right|}{\# H_{i j}^{h}}, \text { if }\left(\# H_{i j}^{h} \neq 0\right) ; h \in\{1,2,3\} \\
0 \quad \text {,otherwise }
\end{gathered}
$$

and

$$
\begin{gathered}
\text { 3, if }\left(\# H_{i j}^{1} \neq 0\right) \wedge\left(\# H_{i j}^{2} \neq 0\right) \wedge\left(\# H_{i j}^{3} \neq 0\right) \\
K=2, i f\left(\# H_{i j}^{a}=0\right) \wedge\left(\left(\# H_{i j}^{b} \neq 0\right) \wedge\left(\# H_{i j}^{c} \neq 0\right)\right) ; a, b, c \in\{1,2,3\}(18) \\
1, \quad \text { otherwise }
\end{gathered}
$$

with $\alpha_{i j}$, a parameter to control the effect of entirety in the assessment of the consistency levels.

$$
\alpha_{i j}=1-\frac{\# E V_{i}+\# E V_{j}-\#\left(E V_{i} \cap E V_{j}\right)}{4(n-1)-2}
$$

$p_{i j}$ is consistent if $C L_{i j}$ is not less than 0.5 . If $p_{i j}$ is not consistent and $\varepsilon p_{i j} \neq 0$, then DM should revise the preferences. If $p_{i j}$ is not consistent and $\varepsilon p_{i j}=0$, then it means more known preferences are needed. More info about incomplete fuzzy preference relations and their mathematical formulations are available in Herrera-Viedma, Chiclana, Herrera \& Alonso ${ }^{63}$. 
Step 2.2 - "Collection of the assessments": Here, these individual evaluations are aggregated to define group opinion. Dominant opinions of customers are reflected with this process. On this line, let $\left\{p_{i j}^{k 1}, p_{i j}^{k 2}, \ldots, p_{i j}^{k L_{k}}\right\}$ be the set of values to be gathered for any $i, j \in R$ and group $\mathrm{k}$ evaluators, and $\bar{W}=\left(-\bar{w}, \ldots, \bar{w}{ }^{k} L_{k}\right)$ be the values related with evaluators in group $\mathrm{k}$. hHere, the induced ordered weighted geometric (IOWG) operator of dimension $L_{k}$ is a function $\Phi_{W}^{G}:(\mathfrak{R} \times \mathfrak{R})^{L_{k}} \rightarrow \mathfrak{R}$ to which a set of weights/weighting vector is related, $W=\left(w_{1}, \ldots, w_{L_{K}}\right)$, such that $w_{l} \in[0,1]$ and $\sum w_{l}=1$, and it is characterized to aggregate the set of second arguments of a list of $\mathrm{L}_{\mathrm{k}}$ two-tuples $\left\{\left\langle\frac{-}{w}, p_{i j}^{k 1}\right\rangle, \ldots,\left\langle\frac{\bar{w}^{k} L_{k}}{w}, p_{i j}^{k L_{k}}\right\rangle\right\}$, in terms of a positive ratio scale, based on the phrase below:

$$
\Phi_{W}^{G}\left\{\left\langle\bar{w}^{k 1}, p_{i j}^{k 1}\right\rangle, \ldots,\left\langle\bar{w}^{k L_{k}}, p_{i j}^{k L_{k}}\right\rangle\right\}=\prod_{l=1}^{L_{k}}\left(p_{i j}^{k[l]}\right)
$$

being: $\{1, \ldots, \mathrm{Lk}\} \rightarrow\{1, \ldots, \mathrm{Lk}\}$, a permutation such that $\bar{w}^{k[l]} \geq \bar{w}^{k[l+1]}, 1=\{1, \ldots$, Lk-1 $\}$, i.e. $\left\{\left\langle\bar{w}^{k[l]}, p_{i j}^{k[l]}\right\rangle\right.$ is the two tuple with $\bar{w}^{k l l}$ the lth highest value in the set $\left\{w^{k 1}, \ldots, \bar{w}^{k L_{k}}\right\} .{ }^{80}$ Based on the ideas by Yager $^{81}$, the IOWG operator represents the fuzzy majority if we calculate its weighting vector $\mathrm{W}$ via a fuzzy linguistic quantifier. Proportional quantifiers such as most, as many as possible, may be represented by fuzzy subsets of the unit interval, [0,1]. Then for any $\mathrm{t} \in[0,1], Q(t)$ demonstrates the degree to which the proportion $t$ is concordant with the meaning of the quantifier it represents. The weights can be acquired as follows for a non-decreasing relative quantifier Q:

$$
w_{k}=Q(k / K)-Q((k-1) / K), \mathrm{k}=1, \ldots, \mathrm{K}
$$

where $Q(t)$ is defined as $\left(\operatorname{Kacprzyk}^{82}\right)$

$$
Q(t)= \begin{cases}0, & \text { if } \quad t<s \\ (t-s) /(v-s), & \text { if } s \leq t \leq v \\ 1, & \text { if } t \geq v .\end{cases}
$$

"Most" $(0.3,0.8)$, "at least half" $(0,0.5)$ and "as many as possible" $(0.5,1)$ are some examples for the relative quantifiers. When the weights of the IOWG operator $\Phi_{W}^{G}$ are calculated, the fuzzy quantifier Q is represented by $\Phi_{Q}^{G}$. Thereof, the collective multiplicative relative importance relation is obtained based on the following expression;

$$
p_{i j}^{k}=\Phi_{Q}^{G}\left(p_{i j}^{k 1}, p_{i j}^{k 2}, \ldots, p_{i j}^{k L_{k}}\right), 1 \leq \mathrm{i} \neq \mathrm{j} \leq \mathrm{N} .
$$

Step 2.3 - "Determining the importance of CNs": to determine the importance weights of $\mathrm{CNs}$, we must take advantage of the group opinion gathered in the matrix $P_{k}$ obtained by Eq. (23. The next step is to quantify the importance of one $\mathrm{CN}$ against others in a fuzzy majority cognation. By using the OWG operator, $\phi_{Q}^{G}$, stated in Herrera, Herrera-Viedma, and Chiclana ${ }^{49}$, we have;

$$
Q G I D_{i}^{k}=1 / 2\left(1+\log _{9} \phi_{Q}^{G}\left(p_{i j}^{k}: j=1, \ldots, N\right)\right)(24)
$$

for all $\mathrm{i}=1, \ldots, \mathrm{N}$.

Actually the OWG operator is a specific state of the IOWG operator where the order inducing values $\bar{W}$ related with the aggregation elements are all equal, i.e., $\quad 1 /|W|$. After normalization, i.e., $Q G I D_{i}^{k}=Q G I D_{i}^{k} / \sum_{i} Q G I D_{i}^{k}$, we have the importance degrees in percentage for the group $\mathrm{k}$. These steps should be sustained in all levels of the evaluation model. The importance degree of each requirement in the hierarchy is computed by multiplying its importance value with the importance values of its up level requirements. Finally, the weighted sum of CN's group importance values is computed to achieve the aggregate $\mathrm{CN}$ importance.

Step 3 - "Detecting the DRs": Initially CNs are transformed to technical attributes. DRs are defined based on the company's operational or managerial plans for the purpose of satisfying the customers. While specifying the DRs, finding direct solutions to defined CNs is the most substantial matter.

Step 4 - "Prioritizing DRs": Here, firstly a relationship matrix is established between $\mathrm{CNs}$ and DRs. Each DRs is correlated separately to each $\mathrm{CNs}$ by considering the degree for the contribution of a requirement in meeting $\mathrm{CNs}$ for the attribute. Depending onto the influence of the DRs in meeting CNs, values "Empty=no relationship", " $1=$ probable relationship", " $3=$ medium relationship", and "9=strong relationship" are assigned.

Then by using the relative importance of every $\mathrm{CN}$ and the relationship matrix, the importance of each DR is calculated. The quality of the relationship matrix heavily affects the accuracy of the results in this step. CNs are interlaced with DRs in this computation process. Namely, the outcome defines the relative weight of each of the DRsagainst CNs. The relative weight of each DR is computed by multiplying the sum 
of each $\mathrm{CN}$ importance value and the measured relationship between the same $\mathrm{CN}$ and the DR in use.

\section{Application of the proposed approach: Development of Portable Entertainment and Game Systems}

With the advent of technology, everything has become much more complex. In the portable entertainment and game systems, major improvements are provided from single-color LCD screen to touch screens that can obtain millions of colors. Thereby to illustrate the proposed approach, "Portable Entertainment and Game Systems" are chosen.

Step 1 - Identifying customers and CNs: Here the important point is that for portable entertainment and game systems, products in the market impress different customer groups from children to adults. According to a research report ${ }^{\mathrm{a}}$, console usage distribution by age is as 2-5 years: 0.05 , 6-11 years: $0.20,12-17$ years: $0.25,18$ 24 years: $0.19,25-34$ years: $0.18,35-44$ years: $0.08,44-$ 54 years: 0.04, and 55+ years: 0.01. Based on this survey, three focus groups namely children (12 years and under), teenagers (12-25 years/mostly students) and adults (25 years and over/working) are selected with $25 \%, 44 \%$ and $31 \%$ importance respectively. In identifying $\mathrm{CNs}$, it is essential to capture the marketing needs from customers' perspective. According to surveys and interviews with the target customer groups, the $\mathrm{CNs}$ are determined as:

CR1: Main factors:

SCR1: gameplay,

SCR2: music,

SCR3: movies/video,

CR2: Technical factors:

SCR4: support to internet connect/wireless,

SCR5: long battery life,

SCR6: strong hardware/system,

CR3: Marketing factors:

SCR7: reasonable price,

SCR8: accessories,

SCR9: ergonomically design.

Step 2 - Prioritizing CNs:

Step 2.1 - Harmonizing Different Relative Evaluations: For example to assess the groups, criteria (main factors, technical factors, marketing factors) evaluations are given respectively.

\footnotetext{
a http://blog.nielsen.com/nielsenwire/media_entertainment/hottestjune-on-record-for-video-gaming/
}

\section{a- Group 1 - Children:}

- Member 1 gives an importance ordering of $\{1,2,3\}$.

- Member 2 provides an incomplete evaluation matrix.

\begin{tabular}{cccc}
\hline & CR1 & CR2 & CR3 \\
\hline CR1 & $*$ & $\mathrm{x}$ & $\mathrm{x}$ \\
$\mathrm{CR} 2$ & $\mathrm{VL}$ & $*$ & $\mathrm{M}$ \\
$\mathrm{CR} 3$ & $\mathrm{x}$ & $\mathrm{x}$ & $*$ \\
\hline
\end{tabular}

- Member 3 states an importance degree vector $\{0.5$, $0.6,0.6\}$.

- Member 4 says 1 and 2 are important than 3.

- Member 5 gives a subset of $\mathrm{CNs}\{\mathrm{r} 1\}$ that is determined as significant.

- Member 6 ensures a subset of $\mathrm{CNs}$ and assigns importance to them in linguistic terms $\{r 1: \mathrm{I}, \mathrm{r} 2: \mathrm{VI}\}$.

- Member 7 evaluates each CNs in linguistic terms $\{\mathrm{I}, \mathrm{I}$, I\}.

With the help of transformation functions stated in section 3 - step 2.1, importance relation matrices $\mathrm{P}^{11}$ to $\mathrm{P}^{17}$ are calculated.

$$
\begin{aligned}
& P^{11}=\begin{array}{|l|l|l|}
\hline 1.00 & 3.00 & 9.00 \\
\hline 0.33 & 1.00 & 3.00 \\
\hline 0.11 & 0.33 & 1.00 \\
\hline
\end{array} P^{12}=\begin{array}{|l|l|l|}
\hline 0.50 & 0.90 & 0.90 \\
\hline 0.10 & 0.50 & 0.50 \\
\hline 0.10 & 0.50 & 0.50 \\
\hline
\end{array} \\
& P^{13}=\begin{array}{|l|l|l|}
\hline 1.00 & 0.83 & 0.83 \\
\hline 1.20 & 1.00 & 1.00 \\
\hline 1.20 & 1.00 & 1.00 \\
\hline
\end{array} P^{14}=\begin{array}{|l|l|l|}
\hline 1.00 & 1.00 & 9.00 \\
\hline 1.00 & 1.00 & 9.00 \\
\hline 0.11 & 0.11 & 1.00 \\
\hline
\end{array} \\
& P^{15}=\begin{array}{|l|l|l|}
\hline 1.00 & 9.00 & 9.00 \\
\hline 0.11 & 1.00 & 1.00 \\
\hline 0.11 & 1.00 & 1.00 \\
\hline
\end{array} P^{16}=\begin{array}{|l|l|l|}
\hline 1.00 & 0.58 & 1.73 \\
\hline 1.73 & 1.00 & 1.73 \\
\hline 0.58 & 0.58 & 1.00 \\
\hline
\end{array} \\
& P^{17}=\begin{array}{|l|l|l|}
\hline 1.00 & 1.00 & 1.00 \\
\hline 1.00 & 1.00 & 1.00 \\
\hline 1.00 & 1.00 & 1.00 \\
\hline
\end{array}
\end{aligned}
$$

To describe this step more clearly, some sample calculations of every member's importance relation matrices are shown as follows.

Member 1: The ordered importance vector of member 1 can be converted into a relative importance relation as $p_{12}^{11}=9^{u_{1}-u_{2}}=9^{1-0.5}=3$ using Eq. (1) where $u_{1}=(3-1) /(3-1)=1$ and $u_{2}=(3-2) /(3-1)=0.5$. 
Member 2: Transforming the incomplete preference matrix of member 2 into a relative importance relation is described below.

Known values are defuzzified using Eq. (7). For instance, defuzzified incomplete evaluation ${ }_{11} p_{21}^{12}$ is calculated as $\mathrm{F}\left(\widetilde{\mathrm{p}}_{21}^{12}\right)=1 / 2 \int_{0}(0+0.2) d \alpha=1 / 2 \times\left. 0.2 \alpha\right|_{0} ^{1}=0.10$.

Eqs. (8) to (10) are used to estimate the missing values.

Iteration 1. One set of elements to estimate is $\{(1,3),(3,1)\}$. With estimation process we have $H_{13}^{1}=\phi$ as $c p_{13}^{21}=p_{12}^{12}+p_{23}^{12}-0.5=$ unknown $H_{13}^{2}=\{1\}$ as $c p_{13}^{22}=p_{23}^{12}-p_{21}^{12}+0.5=0.50-0.10+0.50=0.90$ $H_{13}^{3}=\phi \quad$ as $c p_{13}^{23}=p_{12}^{12}-p_{32}^{12}+0.5=$ unknown, thereby $c p_{13}=0.90$.

$H_{31}^{1}=\phi$ as $c p_{31}^{21}=p_{32}^{12}+p_{21}^{12}-0.5=$ unknown $H_{31}^{2}=\{1\}$ as $c p_{31}^{22}=p_{21}^{12}-p 3+0.5=0.10-0.50+0.50=0.10$ $H_{31}^{3}=\phi \quad$ as $\quad c p_{31}^{23}=p_{32}^{12}-p_{12}^{12}+0.5=$ unknown, thereby $c p_{31}=0.10$.

Iteration 2. Another set of elements to estimate is $\{(1,2),(3,2)\}$. With estimation process we have $H_{12}^{1}=\phi$ as $c p_{12}^{31}=p_{13}^{12}+p_{32}^{12}-0.5=$ unknown $H_{12}^{2}=\phi$ as $c p_{12}^{32}=p_{32}^{12}-p_{31}^{12}+0.5=$ unknown $H_{12}^{3}=\{1\}$ as $c p_{12}^{33}=p_{13}^{12}-p_{23}^{12}+0.5=0.90-0.5+0.5=0.90$, thereby $c p_{12}=0.90$.

$H_{32}^{1}=\phi$ as $c p_{32}^{11}=p_{31}^{12}+p_{12}^{12}-0.5=$ unknown

$H_{32}^{2}=\{1\}$ as $c p_{32}^{12}=p_{12}^{12}-p_{13}^{12}+0.5=$ unknown

$H_{32}^{3}=\phi$ as $c p_{32}^{13}=p_{31}^{12}-p_{21}^{12}+0.5=0.10-0.10+0.50=0.50$, thereby $c p_{23}=0.50$.

Finally, after missing values are found, consistency should be checked. The consistency level matrix is calculated as Table 2.

Table 2. Consistency level matrix for the assessment of member 1 .

\begin{tabular}{cccc}
\hline & Main F. & Technical F. & Marketing F. \\
\hline Main F. & - & 0.58 & 0.50 \\
Technical F. & 0.58 & - & 0.58 \\
Marketing F. & 0.50 & 0.58 & - \\
\hline
\end{tabular}

For instance for $p_{12}^{12}$, the consistency level, computed using Eqs. (11) to (19), is as follows.

$\mathrm{EV} 1=\{(2,1)\} ; \mathrm{EV} 2=\{(2,1),(2,3)\} ; \mathrm{EV} 3=\{(2,3)\}$.

$\mathrm{CP} 1=1 / 4, \mathrm{CP} 2=2 / 4, \mathrm{CP} 3=1 / 4$.

$\alpha_{12}=1-[(1+2-1) / 4(3-1)-2]=0.67$.

For $p_{12}^{12}$, we have not any different alternative value than 0.5 to calculate an estimated value, therefore consequently $\varepsilon p_{12}=0$.
$C L_{12}=(1-0,67) \cdot(1-0)+0,67 \cdot \underline{2 / 4+1 / 4}=0.58$.

Member 3: If the importance degree vector of member 3 is converted into a relative importance relation using Eq.(2), we have $p_{12}^{13}=u_{i} / u_{j}=0.5 / 0.6=0.83$.

Member 4: Here the member says 1 and 2 are more important than 3, but does not mention about the relative importance between then. Therefore, using Eq.(4) $p_{12}^{14}=1$.

Member 5: For $p_{12}^{15}$ where $i=1$ and $j=2$, $i \in R^{\prime}, j \in R / R^{\prime}$ notation is supplied for the subset which member chose. Using Eq.(5), $p_{12}^{15}$ is calculated as 9.

Member 6: The relative importance of member 3 for $p_{12}^{16}$ can be calculated using Eq.(6) as $p_{12}^{16}=9^{0.75-1}=0.58$.

Member 7: The linguistic term vector of member 7 can be converted into a relative importance relation using Eq.(7) as $p_{12}^{17}=9^{0.75-0.75}=1$.

Step 2.2 - "Collection of the assessments": Considering the matrices $\mathrm{P}^{11}-\mathrm{P}^{17}$, with the help of Eqs. (8) and (9), we make use of the IOWG operator with the fuzzy linguistic quantifier "at least half - $(0,0.5)$ " for finding the importance relation matrix of the group. It's weighting vector is found as $(0.2857,0.2857,0.2857$, $0.1429,0,0,0)$.

Then using Eq. (7), (transformed to Eq. (10) with the fuzzy quantifier), group importance relation matrix is as follows.

$$
\mathrm{P}^{1}=\begin{array}{|l|l|l|}
\hline 0.82 & 1.26 & 2.36 \\
\hline 0.40 & 0.82 & 1.54 \\
\hline 0.21 & 0.52 & 0.82 \\
\hline
\end{array}
$$

As an instance, for $p_{12}^{1}$,

$$
\begin{aligned}
& p_{12}^{1}=\prod_{l=1}^{7}\left(p_{12}^{1[l]}\right)^{l}=\Phi_{Q}^{G}\left(p_{12}^{11}, p_{12}^{12}, p_{12}^{13}, p_{12}^{14}, p_{12}^{15}, p_{12}^{16}, p_{12}^{17}\right) \\
& =3.00^{02857} \times 0.90^{22857} \times 0.83^{22857} \times 1.00^{0.1429} \times 9.00^{0} \times 0.58 \times 1.00^{0}=1.26
\end{aligned}
$$

Step 2.3 - "Acquiring priorities from the evaluation matrix": Eqs. (8) and (9) are used again for computing the weighting vector $(0.667,0.333,0)$ corresponding again to the fuzzy linguistic quantifier "at least half." Afterwards, by Eq. (11) group aggregated importance values of $\mathrm{P}^{1}$ are computed.

Then, we can compute the associate importance values of the group 1 as $(0.487,0.345,0.215)$ which are then normalized as $(0.465,0.330,0.205)$. The procedure for the collaborative importance is as follows. $Q G I D_{1}^{1}=1 / 2\left(1+\log _{9} \phi_{Q}^{G}\left(p_{1 j}^{3}: j=1,2,3\right)\right)$ 


$$
\begin{aligned}
& =1 / 2\left(1+\log _{9}\left(0.82^{0.667} \times 1.26^{0.333} \times 2.36^{0}\right)\right)=0.487 \\
Q G I D_{1}^{2} & =1 / 2\left(1+\log _{9} \phi_{Q}^{G}\left(p_{1 j}^{3}: j=1,2,3\right)\right) \\
& =1 / 2\left(1+\log _{9}\left(0.40^{0.667} \times 0.82^{0.333} \times 1.54^{0}\right)\right)=0.345 \\
Q G I D_{1}^{3} & =1 / 2\left(1+\log _{9} \phi_{Q}^{G}\left(p_{1 j}^{3}: j=1,2,3\right)\right) \\
& =1 / 2\left(1+\log _{9}\left(0.21^{0.667} \times 0.52^{0.333} \times 0.82^{0}\right)\right)=0.215
\end{aligned}
$$

The relative quantifiers are decided by the interviewer based on majority concept in the previous and present parts of this study.

\section{b- Group 2 - Teenagers:}

- Member 1 gives an ordered importance vector $\{1,2,3\}$.

- Member 2 states an importance degree vector $\{0.6$, $0.3,0.3\}$

- Member 3 gives an incomplete evaluation matrix.

\begin{tabular}{cccc}
\hline & CR1 & CR2 & CR3 \\
\hline CR1 & $*$ & $\mathrm{x}$ & $\mathrm{x}$ \\
$\mathrm{CR} 2$ & $\mathrm{FL}$ & $*$ & $\mathrm{FG}$ \\
$\mathrm{CR} 3$ & $\mathrm{x}$ & $\mathrm{x}$ & $*$ \\
\hline
\end{tabular}

- Member 4 says 1 and 2 are important than 3.

- Member 5 supplies a subset of CNs $\left\{r^{1}, r^{2}\right\}$ that is found important.

- Member 6 gives an evaluation matrix

\begin{tabular}{cccc}
\hline & CR1 & CR2 & CR3 \\
\hline CR1 & 1 & 1 & 3 \\
CR2 & 1 & 1 & 3 \\
CR3 & $1 / 3$ & $1 / 3$ & 1 \\
\hline
\end{tabular}

- Member 7 evaluates CNs in linguistic terms $\{\mathrm{VI}, \mathrm{I}, \mathrm{I}\}$. Importance relation matrices $\mathrm{P}^{21}$ to $\mathrm{P}^{27}$ are calculated as follows.

$$
\begin{aligned}
P^{21} & =\begin{array}{|l|l|l|}
\hline 1.00 & 3.00 & 9.00 \\
\hline 0.33 & 1.00 & 3.00 \\
\hline 0.11 & 0.33 & 1.00 \\
\hline
\end{array} P^{22}=\begin{array}{|l|l|l|l|}
\hline 1.00 & 2.00 & 2.00 \\
\hline 0.50 & 1.00 & 1.00 \\
\hline 0.50 & 1.00 & 1.00 \\
\hline 0.50 & 0.70 & 0.90 \\
\hline 0.30 & 0.50 & 0.70 \\
\hline 0.10 & 0.30 & 0.50 \\
\hline
\end{array} P^{24}=\begin{array}{|l|l|l|l|}
\hline 1.00 & 1.00 & 9.00 \\
\hline 1.00 & 1.00 & 9.00 \\
\hline 0.11 & 0.11 & 1.00 \\
\hline 1.00 & 1.00 & 9.00 \\
\hline 1.00 & 1.00 & 9.00 \\
\hline 0.11 & 0.11 & 1.00 \\
\hline
\end{array} P^{26}=\begin{array}{|l|l|l|}
\hline 1.00 & 1.00 & 3.00 \\
\hline 1.00 & 1.00 & 3.00 \\
\hline 0.33 & 0.33 & 1.00 \\
\hline
\end{array}
\end{aligned}
$$

$$
P^{27}=\begin{array}{|l|l|l|}
\hline 1.00 & 1.73 & 1.73 \\
\hline 0.58 & 1.00 & 1.00 \\
\hline 0.58 & 1.00 & 1.00 \\
\hline
\end{array}
$$

Step 2.2 - "Collection of the assessments": Considering the matrices $\mathrm{P}^{21}-\mathrm{P}^{27}$, the IOWG operator is used again with quantifier "at least half - $(0,0.5)$ " for finding the group importance relation matrix. Then using Eq. (7), (transformed to Eq. (10) with fuzzy quantifier), group importance relation matrix is as follows.

$$
\mathrm{P}^{2}=\begin{array}{|l|l|l|}
\hline 0.82 & 1.51 & 3.03 \\
\hline 0.42 & 0.82 & 1.69 \\
\hline 0.17 & 0.48 & 0.82 \\
\hline
\end{array}
$$

$\mathrm{As}_{7}$ an instance, for $p_{12}^{2}$,

$p_{12}^{2}=\prod_{l=1}^{7}\left(p_{12}^{2[l]}\right)^{l}=\Phi_{Q}^{G}\left(p_{12}^{21}, p_{12}^{22}, p_{12}^{23}, p_{12}^{24}, p_{12}^{25}, p_{12}^{26}, p_{12}^{27}\right)$

$=3.00^{0.2857} \times 2.00^{0.2857} \times 0.70^{0.2857} \times 1.00^{0.1429} \times 1.00^{0} \times 1.00^{0} \times 1.34=1.51$

Step 2.3 - "Acquiring priorities from the evaluation matrix": The weighting vector corresponding to the quantifier "at least half" is exerted again in this step. Then, Eq. (11) is used for computing group aggregated importance values of $\mathrm{P}^{2}$. The associate importance values of the group 2 are computed as $(0.501,0.355$, $0.172)$ which are then normalized as $(0.487,0.345$, $0.167)$. The procedure for the collaborative importance is as follows.

$$
\begin{aligned}
Q G I D_{2}^{1} & =1 / 2\left(1+\log _{9} \phi_{Q}^{G}\left(p_{1 j}^{3}: j=1,2,3\right)\right) \\
& =1 / 2\left(1+\log _{9}\left(0.82^{0.667} \times 1.51^{0.333} \times 3.03^{0}\right)\right)=0.501 \\
Q G I D_{2}^{2} & =1 / 2\left(1+\log _{9} \phi_{Q}^{G}\left(p_{1 j}^{3}: j=1,2,3\right)\right) \\
& =1 / 2\left(1+\log _{9}\left(0.42^{0.667} \times 0.82^{0.333} \times 1.69^{0}\right)\right)=0.355 \\
Q G I D_{2}^{3} & =1 / 2\left(1+\log _{9} \phi_{Q}^{G}\left(p_{1, j}^{3}: j=1,2,3\right)\right) \\
& =1 / 2\left(1+\log _{9}\left(0.17^{0.667} \times 0.48^{0.333} \times 0.82^{0}\right)\right)=0.172
\end{aligned}
$$

\section{c- Group 3 - Adults:}

- Member 1 states an importance degree vector $\{0.4$, $0.3,0.2\}$

- Member 2 rates CNs in linguistic terms $\{\mathrm{I}, \mathrm{MI}, \mathrm{NI}\}$.

- Member 3 provides an importance ordering $\{1,2,3\}$.

- Member 4 provides an incomplete evaluation matrix. 


\begin{tabular}{cccc}
\hline & CR1 & CR2 & CR3 \\
\hline CR1 & $*$ & $\mathrm{x}$ & $\mathrm{FG}$ \\
$\mathrm{CR} 2$ & $\mathrm{x}$ & $*$ & $\mathrm{FG}$ \\
$\mathrm{CR} 3$ & $\mathrm{x}$ & $\mathrm{x}$ & $*$ \\
\hline
\end{tabular}

- Member 5 supplies a subset of CNs $\left\{\mathrm{r}^{2}\right\}$ that is found important.

- Member 6 gives an evaluation matrix.

\begin{tabular}{cccc}
\hline & CR1 & CR2 & CR3 \\
\hline CR1 & 1 & 2 & 3 \\
CR2 & $1 / 2$ & 1 & 3 \\
CR3 & $1 / 3$ & $1 / 3$ & 1 \\
\hline
\end{tabular}

- Member 7 ensures a subset of CNs and assigns importance to them in linguistic terms $\left\{\mathrm{r}^{2}: \mathrm{MI}\right\}$.

Importance relation matrices $\mathrm{P}^{31}$ to $\mathrm{P}^{36}$ are calculated as:

$$
\begin{aligned}
& P^{31}=\begin{array}{|l|l|l|}
\hline 1.00 & 1.33 & 2.00 \\
\hline 0.75 & 1.00 & 1.50 \\
\hline 0.50 & 0.67 & 1.00 \\
\hline
\end{array} \quad P^{32}=\begin{array}{|l|l|l|}
\hline 1.00 & 1.73 & 5.20 \\
\hline 0.58 & 1.00 & 3.00 \\
\hline 0.19 & 0.33 & 1.00 \\
\hline
\end{array} \\
& P^{33}=\begin{array}{|l|l|l|}
\hline 1.00 & 3.00 & 9.00 \\
\hline 0.33 & 1.00 & 3.00 \\
\hline 0.11 & 0.33 & 1.00 \\
\hline
\end{array} P^{34}=\begin{array}{|l|l|l|}
\hline 0.50 & 0.50 & 0.70 \\
\hline 0.50 & 0.50 & 0.70 \\
\hline 0.30 & 0.30 & 0.50 \\
\hline
\end{array} \\
& P^{35}=\begin{array}{|l|l|l|}
\hline 1.00 & 0.11 & 1.00 \\
\hline 9.00 & 1.00 & 9.00 \\
\hline 1.00 & 0.11 & 1.00 \\
\hline
\end{array} \quad P^{36}=\begin{array}{|l|l|l|l|}
\hline 1.00 & 2.00 & 3.00 \\
\hline 0.50 & 1.00 & 3.00 \\
\hline 0.33 & 0.33 & 1.00 \\
\hline
\end{array} \\
& P^{37}=\begin{array}{|l|l|l|}
\hline 1.00 & 1.00 & 1.00 \\
\hline 1.00 & 1.00 & 1.00 \\
\hline 1.00 & 1.00 & 1.00 \\
\hline
\end{array}
\end{aligned}
$$

Step 2.2 - "Collection of the assessments": Considering the matrices $\mathrm{P}^{31}-\mathrm{P}^{37}$, quantifier "at least half - $(0,0.5)$ " is used again with IOWG operator. Then using Eq. (7), (transformed to Eq. (10) with fuzzy quantifier), group importance relation matrix is as follows.

$$
\mathrm{P}^{3}=\begin{array}{|l|l|l|}
\hline 0.91 & 1.57 & 3.31 \\
\hline 0.52 & 0.91 & 1.91 \\
\hline 0.25 & 0.43 & 0.91 \\
\hline
\end{array}
$$

Step 2.3 - "Acquiring priorities from the evaluation matrix": The weighting vector corresponding again to the fuzzy linguistic quantifier "at least half" is used in this step. Then, Eq. (11) is used for computing group aggregated importance values of $\mathrm{P} 3$. The collaborative importance values of the group 3 are calculated as $(0.520,0.394,0.224)$ which are then normalized as $(0.457,0.346,0.197)$. The procedure for the collaborative importance is as follows.

$$
\begin{aligned}
Q G I D_{3}^{1} & =1 / 2\left(1+\log _{9} \phi_{Q}^{G}\left(p_{1,1}^{3}: j=1,2,3\right)\right) \\
& =1 / 2\left(1+\log _{9}\left(0.90^{1067} \times 1.57^{0.333} \times 3.31^{0}\right)\right)=0.520 \\
Q G I D_{3}^{2} & =1 / 2\left(1+\log _{9} \phi_{Q}^{G}\left(p_{1:}^{3}: j=1,2,3\right)\right) \\
& =1 / 2\left(1+\log _{9}\left(0.50^{2.667} \times 0.91^{0.333} \times 1.91^{0}\right)\right)=0.394 \\
Q G I D_{3}^{3} & =1 / 2\left(1+\log _{9} \phi_{Q}^{G}\left(p_{11}^{3}: j=1,2,3\right)\right) \\
& =1 / 2\left(1+\log _{9}\left(0.25^{0^{0.667}} \times 0.43^{0.333} \times 0.91^{0}\right)\right)=0.224
\end{aligned}
$$

Step 3 - "Defining DRs": After the overall importance weights of CNs are found for all groups, based on surveys, and also expert views that have expertise in this topic, DRs are determined as:

DR1: faster redesigned CPU,

DR2: advanced easily upgradeable system software with codes,

DR3: memory card input, lithium-ion battery,

DR4: wide screen TFT LCD display,

DR5: flexible design for add-on accessories,

DR6: IEEE $802.11 \mathrm{~b}$ wireless,

DR7: touch sensitive buttons,

DR8: upgradeable web browser.

Step 4 - "Prioritizing DRs": The remaining step encompasses the identification of the relationships of CNs with DRs and then, prioritizing these activities so as to create an action plan. Here, a matrix is constructed with the help of experts and relationships are assigned. The accuracy of the outcome heavily based on how qualified the relationship matrix is. Therefore, the relations are negociated comprehensively and a consensus decision is reached. Relation matrix is shown in the final HOQ matrix in Table 3.

\section{Verification of the study}

To indicate the validity and credibility of the studied method with incomplete preferences, we compare the results with a different existing approach which is proposed by Wang and Chen ${ }^{67}$. In their paper named "Incomplete fuzzy linguistic preference relations under uncertain environments", the authors also focus on the same situation, i.e. the availability of partial information. Wang and Chen's approach differs 
in the use of fuzzy linguistic evaluation variables instead of crisp values of incomplete fuzzy preference relations. Computational procedure is as follows.

Suppose that there is a set of alternatives, and a fuzzy reciprocal multiplicative preference matrix $\widetilde{A}_{i j}=\left(\widetilde{a}_{i j}\right)$ with $a_{i j} \in[1 / 9,9]$ connected to this set, then the corresponding fuzzy reciprocal linguistic preference relation $\widetilde{P}=\left(\widetilde{p}_{i j}\right)$ demonstrates an additive reciprocal, i.e., the statements below are equivalent:

$$
\begin{aligned}
& p_{i j}^{L}+p_{j i}^{R}=1 \forall i, j \in\{1, \ldots, n\} . \\
& p_{i j}^{M}+p_{j i}^{M}=1 \forall i, j \in\{1, \ldots, n\} . \\
& p_{i j}^{R}+p_{j i}^{L}=1 \forall i, j \in\{1, \ldots, n\} .
\end{aligned}
$$

Also if a reciprocal fuzzy linguistic preference relation $\widetilde{P}=\left(\widetilde{p}_{i j}\right)=\left(\widetilde{p}_{i j}^{L}, \widetilde{p}_{i j}^{M}, \widetilde{p}_{i j}^{R}\right)$ is consistent, then the statements below are equivalent:

$$
\begin{gathered}
p_{i j}^{L}+p_{j k}^{L}+p_{k i}^{R}=3 / 2 \forall i<j<k . \\
p_{i j}^{M}+p_{j k}^{M}+p_{k i}^{M}=3 / 2 \forall i<j<k . \\
p_{i j}^{R}+p_{j k}^{R}+p_{k i}^{L}=3 / 2 \forall i<j<k . \\
p_{i(i+1)}^{L}+p_{(i+1)(i+2)}^{L}+\ldots+p_{(j-1) j}^{L}+p_{j i}^{R}=(j-i-1) / 2 \forall i<j .(31) \\
p_{i(i+1)}^{M}+p_{(i+1)(i+2)}^{M}+\ldots+p_{(j-1) j}^{M}+p_{j i}^{M}=(j-i-1) / 2 \forall i<j .(32) \\
p_{i(i+1)}^{R}+p_{(i+1)(i+2)}^{r}+\ldots+p_{(j-1) j}^{R}+p_{j i}^{L}=(j-i-1) / 2 \forall i<j .(33)
\end{gathered}
$$

More detailed information can be seen in Wang and Chen's paper ${ }^{67}$. According to computations, the results show that overall importance is same in both approaches. If we apply this method to find the missing values in each group's incomplete decision matrices, we acquire the following computations.

For member 2 of group 'Children':

\begin{tabular}{lccc}
\hline & $\mathrm{CR} 1$ & $\mathrm{CR} 2$ & $\mathrm{CR} 3$ \\
\hline $\mathrm{CR} 1$ & $*$ & $\left(p_{12}^{L}, p_{12}^{M}, p_{12}^{R}\right)$ & $\left(p_{13}^{L}, p_{13}^{M}, p_{13}^{R}\right)$ \\
$\mathrm{CR} 2$ & $(0,0.1,0.2)$ & $*$ & $(0.4,0.5,0.6)$ \\
$\mathrm{CR} 3\left(p_{31}^{L}, p_{31}^{M}, p_{31}^{R}\right)$ & $\left(p_{32}^{L}, p_{32}^{M}, p_{32}^{R}\right)$ & $*$ \\
\hline
\end{tabular}

$p_{12}^{L}+p_{21}^{R}=1$, thereby $p_{12}^{L}=1-0.2=0.8$.

$p_{12}^{M}+p_{21}^{M}=1$, thereby $p_{12}^{M}=1-0.1=0.9$.
$p_{12}^{R}+p_{21}^{L}=1$, thereby $p_{12}^{R}=1-0=1$.

$p_{32}^{L}+p_{23}^{R}=1$, thereby $p_{32}^{L}=1-0.6=0.4$.

$p_{32}^{M}+p_{23}^{M}=1$, thereby $p_{32}^{M}=1-0.5=0.5$.

$p_{32}^{R}+p_{23}^{L}=1$, thereby $p_{32}^{R}=1-0.4=0.6$.

$p_{13}^{L}+p_{32}^{L}+p_{21}^{R}=3 / 2$, thereby $p_{13}^{L}=1.5-0.4-0.2=0.9$.

$p_{13}^{M}+p_{32}^{M}+p_{21}^{M}=3 / 2$, thereby $p_{13}^{M}=1.5-0.5-0.1=0.9$.

$p_{13}^{R}+p_{32}^{R}+p_{21}^{L}=3 / 2$, thereby $p_{13}^{R}=1.5-0.6-0=0.9$.

$p_{31}^{L}+p_{13}^{R}=1$, thereby $p_{31}^{L}=1-0.9=0.1$.

$p_{31}^{L}+p_{13}^{R}=1$, thereby $p_{31}^{M}=1-0.9=0.1$.

$p_{31}^{L}+p_{13}^{R}=1$, thereby $p_{31}^{R}=1-0.9=0.1$.

And the estimated matrix is:

\begin{tabular}{ccc}
\hline CR1 & CR2 & CR3 \\
\hline CR1 $(0.5,0.5,0.5)$ & $(0.8,0.9,1)$ & $(0.9,0.9,0.9)$ \\
CR2 & $(0,0.1,0.2)$ & $(0.5,0.5,0.5)(0.4,0.5,0.6)$ \\
CR3 $(0.1,0.1,0.1)(0.4,0.5,0.6)(0.5,0.5,0.5)$ \\
\hline
\end{tabular}

If we deffuzify the values with Eq.(7), we acquire the same values as in Section 4 - Step 2.1.

$$
P^{12}=\begin{array}{|l|l|l|}
\hline 0.50 & 0.90 & 0.90 \\
\hline 0.10 & 0.50 & 0.50 \\
\hline 0.10 & 0.50 & 0.50 \\
\hline
\end{array}
$$

Similarly for groups 'Teenagers' and 'Adults', we obtained same outputs in both approaches for the incomplete preferences given by members. The missing preference computations resulted as expected; this means that the approach of our study is consistent and valid. Furthermore, we believe that the approach for controlling the consistency level and estimating errors is more clear and strong in the proposed method of Herrera-Viedma et al. ${ }^{62}$, which is implemented in this study.

\section{Concluding Remarks}

Being a customer focused quality management system; HOQ for product improvement includes great input data gathered from QFD team members. However, based on their background and experience, team members supply information about their preferences in various ways. As DMs state their preferences over alternatives in diversified structures, a fuzzy logic based QFD approach is developed to solve such a GDM problem. The prioritization of CNs is the key step in QFD for 
acquiring the importance of DRs, thereby we believe that further significance should be given to analyze and associate relative personal evaluations in various even incomplete formats.

In this paper, we studied a method that helps us to merge both qualitative (linguistic) and quantitative (numerical) data for QFD; and we detected the CNs' importance values using the fuzzy majority concept in a new application "Portable Entertainment and Game Systems".

To summarize the study, the main contributions may be underlined as follows:

- The main topics of the study have been investigated and presented comprehensively in the literature review.

- Multiple preference relations help to combine different types of evaluations and increase the flexibility in the GDM process.

- This study can be stated as one of the pioneers in the literature because of applying multiple preference formats including incomplete preferences. Since customers are allowed to give different formats of expressions instead of precise terms, the approach is helpful for stating the weights of the CNs.

- As the proposed approach prevents the decrement of information and the lack of certainty, the evaluations acquired from customers and designers are handled more accurately.

Extended studies can include the use of different aggregation operators other than this proposed method $^{81,83}$.

\section{Acknowledgements}

This study is partially supported by The Scientific and Technological Research Council of Turkey (TUBITAK) in the scope of 109M147 numbered research project. The authors would like to thank TUBITAK for financial support. The authors thank the Editor, Professor Prof. $\mathrm{Jie} \mathrm{Lu}$, and anonymous reviewers for their valuable comments and suggestions to improve the early version of the paper.

\section{References}

1. N. B. Reilly, The Team based product development guidebook (ASQ Quality Press, Milwaukee Wisconsin, 1999)
2. L. P. Sullivan, Quality function deployment, Quality Progress 19(6) (1986) 39-50.

3. J. R. Hauser and D. Clausing, The house of quality. Harvard Business Review 66(3) (1988) 63-73.

4. O. Feyzioğlu, and G. Büyüközkan, An integrated group decision-making approach for new product development, International Journal of Manufacturing 21(4) (2008) 366-375.

5. H. Raharjo, A. C. Brombacher and M. Xie, Dealing with subjectivity in early product design phase: A systematic approach to exploit Quality Function Deployment potentials, Computers \& Industrial Engineering $\mathbf{5 5}$ (2008) 253-278.

6. M. Celik, S. Cebi, C. Kahraman, and I. D. Er, An integrated fuzzy QFD model proposal on routing of shipping investment decisions in crude oil tanker market, Expert Systems with Applications 36(3) (2009) 62276235.

7. C. Güngör Şen and H. Baraçl1, Fuzzy quality function deployment based methodology for acquiring enterprise software selection requirements, Expert Systems with Applications 37(4) (2010) 3415-3426.

8. C. -H. Lo, K. C. Tseng and C.-H. Chu, One-Step QFD based 3D morphological charts for concept generation of product variant design, Expert Systems with Applications 37(11) (2010) 7351-7363.

9. L. Y. Zhai, L. P. Khoo and Z. W. Zhong, Towards a QFD-based expert system: A novel extension to fuzzy QFD methodology using rough set theory, Expert Systems with Applications 37(12) (2010) 8888-8896.

10. C. - H. Wang and J. -N. Chen, Using quality function deployment for collaborative product design and optimal selection of module mix, Computers \& Industrial Engineering 63(4) (2012) 1030-1037.

11. G. Büyüközkan and O. Feyzioğlu, Group decision making to better respond customer needs in software development, Computers \& Industrial Engineering 48 (2005) 427-441.

12. C. -H. Liu and H. -H. Wu, A fuzzy group decisionmaking approach in quality function deployment, Quality \& Quantity 42 (2008) 527-540.

13. Z. Zhang and X. Chu, Fuzzy group decision-making for multi-format and multi-granularity linguistic judgments in quality function deployment, Expert Systems with Applications 36 (2009) 9150-9158.

14. Y. -M. Wang and K. -S. Chin, A linear goal programming approach to determining the relative importance weights of customer requirements in quality function deployment, Information Sciences 181(24) (2011) 5523-5533.

15. Y. Chen, R. Y. K. Fung and J. Tang, Rating technical attributes in fuzzy QFD by integrating fuzzy weight average method and fuzzy expected value operator, European Journal of Operational Research 174 (2006) 1553-1566.

16. T. -C. Kuo, H. - H. Wu and J. -I. Shieh, Integration of environmental considerations in quality function 
deployment by using fuzzy logic, Expert Systems with Applications 36 (2009) 7148-7156.

17. Y. H. Lin, H. -P. Cheng, M. -L. Tseng and J. C. C. Tsai, Using QFD and ANP to analyze the environmental production requirements in linguistic preferences, Expert Systems with Applications 37 (2010) 2186-2196.

18. Y. -M. Wang, A fuzzy-normalisation-based group decision-making approach for prioritising engineering design requirements in QFD under uncertainty, International Journal of Production Research 50(23) (2011) 6963-6977.

19. G. -S. Liang, J. -F. Ding and C. -K. Wang, Applying fuzzy quality function deployment to prioritize solutions of knowledge management for an international port in Taiwan, Knowledge-Based Systems 33 (2012) 83-91.

20. F. Chiclana, F. Herrera and E. Herrera-Viedma, Integrating multiplicative preference relations in a multipurpose decision making model based on fuzzy preference relations, Fuzzy Sets and Systems 122(2) (2001) 277-291.

21. $\mathrm{Z}$. $\mathrm{Xu}, \mathrm{A}$ method based on linguistic aggregation operators for group decision making with linguistic preference relations, Information Sciences 166 (2004) 19-30.

22. Q. Zhang, J. C. H. Chena and P. P. Chong, Decision consolidation: criteria weight determination using multiple preference formats, Decision Support Systems 38 (2004) 247-258.

23. G. Büyüközkan, O. Feyzioğlu and D. Ruan, Fuzzy group decision-making to multiple preference formats in quality function deployment, Computers in Industry 58(5) (2007) 392-402.

24. Z. Zhang and X. Chu, A new integrated decision-making approach for design alternative selection for supporting complex product development, International Journal of Computer Integrated Manufacturing 22(3) (2009) 179198.

25. G. Büyüközkan and G. Çifçi, A new incomplete preference relations based approach to quality function deployment, Information Sciences 206(5) (2012) 30-41.

26. Y. -I. Li, J. -F. Tang, K. -S. Chin, X. -G. Luo, Y. Pu and Y. -S. Jiang, On integrating multiple type preferences into competitive analyses of customer requirements in product planning. International Journal of Production Economics 139(1) (2012) 168-179.

27. G. Büyüközkan and G. Çifçi, An integrated QFD framework with multiple formatted and incomplete preferences: A sustainable supply chain application, Applied Soft Computing 13(9) (2013) 3931-3941.

28. L. A. Zadeh, Fuzzy set, Information and Control 8 (1965) 338-353.

29. S. Mizuno and Y. Akao, QFD: The Customer-Driven Approach to Quality Planning and Development (Asian Productivity Organization, 1994).

30. K. Hofmeister and B. Slabey, Quality Function Deployment (Basic Books, NY, 1988).
31. C. Nicholson, Quality Function Deployment (Blount Inc., Portland, OR, 1990).

32. G. Herzwurm, S. Schockert and W. Mellis, Determining the success of a QFD project, in Proceedings of the 8th QFD-Symposium (1996), pp. 131-150.

33. A. Herrmann, F. Huber, R. Algesheime and T. Tomczak, An empirical study of quality function deployment on company performance, International Journal of Quality \& Reliability Management 23(4) (2006) 345-366.

34. Ş. Özgener, Quality function deployment: a teamwork approach, Total Quality Management \& Business Excellence 14(9) (2003) 969-979.

35. Y. Akao, Development History of Quality Function Deployment, The Customer Driven Approach to Quality Planning and Deployment (Asian Productivity Organization, 1994, 339).

36. T. N. Gladwin, J. J. Kennelly and T. Krause, Shifting paradigms for sustainable development: implications for management theory and research, Academy of Management Review 20 (1995) 874-907.

37. G. Çifçi and G. Büyüközkan, A Fuzzy MCDM Approach to Evaluate Green Suppliers, International Journal of Computational Intelligence, 4(5) (2011) 894-909.

38. T. Gürbüz, Y. E. Albayrak and E. Alaybeyoğlu, Criteria Weighting and 4P's Planning in Marketing Using a Fuzzy Metric Distance and AHP Hybrid Method, International Journal of Computational Intelligence, 7(1) (2014) 94104.

39. Z. Hu, Z. Chen, Z. Pei, X. Ma and W. Liu, An Improved Ranking Strategy for Fuzzy Multiple Attribute Group Decision Making, International Journal of Computational Intelligence, 6(1) (2013) 38-46.

40. Y. Ruana, Z. Peia and Z. Gaoa, Linguistic interval 2tuple power aggregation operators and their applications, International Journal of Computational Intelligence, 6(2) (2013) 381-395.

41. M. Bevilacqua, F. E. Ciarapica and G. Giacchetta, A fuzzy-QFD approach to supplier selection, Journal of Purchasing and Supply Management 12 (2006) 14-27.

42. K. -S. Chin, Y. -M. Wang, J. -B. Yang and K. K. G. Poon, An evidential reasoning based approach for quality function deployment under uncertainty, Expert Systems with Applications 36 (2009) 5684-5694.

43. C. -H. Liu, The Development and Application of a Group Decision Model using Fuzzy Logic: The Case of Consumer Attitudes towards Risk, International Journal of Management 26(2) (2009) 261-271.

44. C. K. Kwong, Y. Ye, Y. Chen and K. L. Choy, A novel fuzzy group decision-making approach to prioritising engineering characteristics in QFD under uncertainties. International Journal of Production Research 49(19) (2011) 5801-5820.

45. L. -Z. Lin, L. -C. Huang and H. -R. Yeh, Fuzzy Group Decision-Making for Service Innovations in Quality Function Deployment, Group Decision and Negotiation 21(4) (2012) 495-517. 
46. L. -H. Chen, W. -C. Ko and C-Y. Tseng, Fuzzy Approaches for Constructing House of Quality in QFD and Its Applications: A Group Decision-Making Method, IEEE Transactions on Engineering Management 60(1) (2013) 77-87.

47. S. Zaim, M. Sevkli, H. Camgöz-Akdag, O. F. Demirel, A. Y. Yayla and Dursun Delen, Use of ANP weighted crisp and fuzzy QFD for product development, Expert Systems with Application 41 (2014) 4464-4474.

48. F. Chiclana, F. Herrera and E. Herrera-Viedma, Integrating three representation models in fuzzy multipurpose decision making based on fuzzy preference relations, Fuzzy Sets and Systems 97 (1998) 33-48.

49. F. Herrera, E. Herrera-Viedma and F. Chiclana, Multiperson decisionmaking based on multiplicative preference relations, European Journal of Operational Research 129(2) (2001) 372-385.

50. F. Herrera, L. Martinez and P. J. Sanchez, Managing nonhomogeneous information in group decision making, European Journal of Operational Research 166(1) (2005) 115-132.

51. R. C. -W. Kwok, D. Zhou, Q. Zhang and J. Ma, A fuzzy multi-criteria decision making model for IS student group project assessment, Group Decision and Negotiation 16 (2007) 25-42.

52. Z. Xu, Multiple-attribute group decision making with different formats of preference information on attributes, IEEE Transactions on Systems, Man, and CyberneticsPart B: Cybernetics 37(6) (2007) 1500-1511.

53. Z. Xu, Group decision making based on multiple types of linguistic preference relations, Information Sciences 178(2) (2008) 452-467.

54. Z. S. Xu and J. Chen, MAGDM Linear-Programming models with distinct uncertain preference structures, IEEE Transactions on Systems, Man, and CyberneticsPart B: Cybernetics 38(5) (2008) 1356-1370.

55. F. Abedin, K. -M. Chao, N. Godwin, and H. Arochena, Preference ordering in agenda based multi-issue negotiation for service level agreement, in International Conference on Advanced Information Networking and Applications Workshops (2009), pp. 19-24.

56. Y. Dong, Y. Xu, and S. Yu, Linguistic multiperson decision making based on the use of multiple preference relations, Fuzzy Sets and Systems 160 (2009) 603-623.

57. L. -Z. Lin, Fuzzy multi-linguistic preferences model of service innovations at wholesale service delivery. Quality and Quantity 44(5) (2010) 217-237.

58. E. Herrera-Viedma, S. Alonso, F. Chiclana and F. Herrera, A Consensus Model for Group Decision Making With Incomplete Fuzzy Preference Relations, IEEE Transactions on Fuzzy Systems 15(5) (2007) 863-877.

59. S. Alonso, E. Herrera-Viedma, F. Herrera, F. J. Cabrerizo and F. Chiclana, A Decision Aid System to Provide Consistent Linguistic Preference Relations, in Proceedings of the 6th International Conference on Recent Advances in Soft Computing (2006), pp. 130-135.
60. Z. $\mathrm{Xu}$, Incomplete linguistic preference relations and their fusion, Information Fusion 7 (2006) 331-337.

61. Z. Xu, Integrating Multiple Types of Incomplete Linguistic Preference Relations in Multi-person Decision Making, Fuzzy Systems and Knowledge Discovery, Lecture Notes in Computer Science 4223 (2006) 300309.

62. Z. Xu, Intuitionistic preference relations and their application in group decision making, Information Sciences 177 (2007) 2363-2379.

63. E. Herrera-Viedma, F. Chiclana, F. Herrera and S. Alonso, Group Decision-Making Model with Incomplete Fuzzy Preference Relations Based on Additive Consistency, IEEE Transactions on Systems, Man, and Cybernetics-Part B: Cybernetics 1 (2007) 176-189.

64. M. Fedrizzi and S. Giove, Incomplete pairwise comparison and consistency optimization, European Journal of Operation Research 183 (2007) 303-313.

65. F. Chiclana, E. Herrera-Viedma and S. Alonso, A Note on Two Methods for Estimating Missing Pairwise Preference Values, IEEE Transactions On Systems, Man, And Cybernetics-Part B: Cybernetics 39(6) (2009) 1628-1633.

66. T. -C. Wang, S. -C. Peng, S.-C. Hsu and J. Chang, The Evaluation of the Incomplete Linguistic Preference Relations on the Performance of Web Shops, in 9th International Conference on Hybrid Intelligent Systems (2009), pp. 363-368.

67. T. -C. Wang and Y. -H. Chen, Incomplete fuzzy linguistic preference relations under uncertain environments, Information Fusion 11 (2010) 201-207.

68. C. Porcel and E. Herrera-Viedma, Dealing with incomplete information in a fuzzy linguistic recommender system to disseminate information in university digital libraries, Knowledge-Based Systems $\mathbf{2 3}$ (2010) 32-39.

69. F. J. Cabrerizo, R. P. Heradio, I. J. Pérez and E. HerreraViedma, A selection process based on additive consistency to deal with incomplete fuzzy linguistic information, Journal of Universal Computer Science $\mathbf{1 6}$ (2010) 62-81.

70. F. J. Cabrerizo, I. J. Pérez and E. Herrera-Viedma, Managing the consensus in group decision making in an unbalanced fuzzy linguistic context with incomplete information, Knowledge-Based Systems 23 (2010) 169 181.

71. Y. Xu, On group decision making with four formats of incomplete preference relations, Computers \& Industrial Engineering 61(1) (2011) 48-54.

72. S.-M.Chen, T.-E. Lin and L.-W. Lee, Group decision making using incomplete fuzzy preference relations based on the additive consistency and the order consistency, Information Sciences 259 (2014) 1-15.

73. F. Liu and W.-G. Zhang, TOPSIS-Based Consensus Model for Group Decision-Making with Incomplete Interval Fuzzy Preference Relations, IEEE Transactions on Cybernetics 44(8) (2014). 
74. X. T. Wang and W. Xiong, An integrated linguistic based group decision making approach for quality function deployment, Expert Systems with Applications 38(1) (2011) 14428-14438.

75. Y- Wang, A criteria weighting approach by combining fuzzy quality function deployment with relative preference relation, Applied Soft Computing 14 (2014) 419-430.

76. R. Urena, F. Chiclana, S. Alonsc, J. A. MorenteMolineraa and E. Herrera-Viedmaa, On Incomplete Fuzzy and Multiplicative Preference Relations In MultiPerson Decision Making 31 (2014) 793-801.

77. C. H. Han, J. K. Kim and S. H. Choi, Prioritizing engineering characteristics in quality function deployment with incomplete information: a linear partial ordering approach, International Journal of Production Economics 91 (2004) 235-249.

78. T. L. Saaty, The analytic hierarchy process (McGrawHill Book Co., NY, 1980).

79. Th. L. Saaty, Exploring the interface between hierarchies, multiple objectives and fuzzy sets, Fuzzy Sets and Systems 1 (1978) 57-68.

80. F. Chiclana, E. Herrera-Viedma, F. Herrera and S. Alonso, Induced ordered weighted geometric operators and their use in the aggregation of multiplicative preference relations, International Journal of Intelligent Systems 19 (2004) 233-255.

81. R. R. Yager, On ordered weighted averaging aggregation operators in multicriteria decision-making, IEEE Transactions on Systems, Man and Cybernetics 18 (1988) 183-190.

82. J. Kacprzyk, Group decision making with a fuzzy linguistic majority, Fuzzy Sets and Systems 18(2) (1986) $105-118$.

83. J. I. Pelaez and J. M. Dona, Majority Additive-Ordered Weighting Averaging: A New Neat Ordered Weighting Averaging Operators Based on the Majority Process, International Journal of Intelligent Systems 18(4) (2003) 469-481. 